\title{
Numerical research on thermal decomposition reaction kinetics of large particle size limestone XING Tianyue $^{1, a}$, WANG zhengdong ${ }^{1, b}$ \\ ${ }^{1}$ East China University of Science and Technology, Shanghai, China \\ ${ }^{2}$ East China University of Science and Technology, Shanghai, China \\ acynthia86yue@sina.com, bwangzd@ecust.edu.cn
}

Keywords: Limestone; Thermal decomposition reaction; Numerical analysis method; Reaction mechanism model; Kinetics parameters

\begin{abstract}
Large particle size limestone $\left(\mathrm{CaCO}_{3}\right)$ is an important raw material used in many branches of industry. For lacking of reaction parameters of large particle size limestone, numerical analysis method is used to study the decomposition reaction kinetics of limestone to understand the thermal decomposition reaction and obtain dominant parameters of large particle size limestone (20, $30,40 \mathrm{~mm}$ ). The results show that the decomposition reactions of three different particle sizes at $900 \sim 1000^{\circ} \mathrm{C}$ temperature conform to the phase interface reaction mechanism model (cylindrical symmetry), and the reaction activation energy $E$ is ranging from 30 to $34 \mathrm{kcal} / \mathrm{mol}$ and the pre-exponential factor $\ln A$ is ranging from 7.5 to $9 \mathrm{~s}^{-1}$, which are conference data for practical engineering.
\end{abstract}

\section{Introduction}

Limestone $\left(\mathrm{CaCO}_{3}\right)$ is an important raw material used in many branches of industry, such as, construction, metallurgy, pharmaceuticals and paper industry. Thermal decomposition reaction of limestone plays an important role in practical production. Usually, the main methods of limestone decomposition reaction mechanism are thermo-gravimetric and numerical analysis methods. Thermo-gravimetric method is only applicable to researching limestone with particle size less than $10 \mathrm{~mm}$, restricted by experimental equipments. At present, the design of lime kiln and the control of lime production process mostly depend on numerical method.

There are some researchers, who have studied on limestone decomposition reaction of small particle size limestone. The limestone of $45-90$ microns particle size at $750-900^{\circ} \mathrm{C}$ temperature was performed by S.J.Wang and J.D.Lu ${ }^{[1]}$ investigating the limestone decomposition reaction. Chen $\mathrm{Hai}^{[2]}$ analyzed the limestone of $1-5 \mathrm{~mm}$ particle size, and the obtained limestone decomposition reaction mechanism. However, there is very less published information available for limestone decomposition reaction of large particle size. Limestone with large particle sizes (more than $10 \mathrm{~mm}$ ) are widely used in industrial production. Some key parameters are involved in numerical analysis of large particle sizes, which provide dominant parameters for setting up the thermal simulation equation and realizing online simulation in lime kilns.

In this work, the mechanism of thermal decomposition reaction kinetic parameters of 20,30 , $40 \mathrm{~mm}$ diameter limestone are studied at temperature $900,950,1000^{\circ} \mathrm{C}$ using numerical analysis method. Based on the results of this work, further establishing thermal equation and selecting reaction conditions can be obtained.

\section{Numerical analysis method}

For exploring limestone decomposition reaction kinetics, the numerical equation is firstly solved, concentration profiles under different temperature and particle size are obtained. Secondly, the decomposition reaction mechanisms are determined and related kinetic parameters are dominated.

\section{Concentration profile between limestone decomposition rate and time}

The first step of decomposition reaction research is obtaining concentration profiles between decomposition rate and time, which are acquired through numerical analysis equation. The thermal 
decomposition reaction consists of five sub-processes ${ }^{[3]}$ including: (a) heat transfer from the ambient to the solid surface, (b) heat conduction from the surface to the reaction front, (c) chemical reaction at the front, (d) diffusion of $\mathrm{CO}_{2}$ through the porous oxide layer to the surface, (e) the mass transfer of $\mathrm{CO}_{2}$ into surroundings.

Based on limestone decomposition reaction five sub processes, Szekely et al. ${ }^{[4]}$ and Kainer et al. ${ }^{[5]}$ derived a coupled differential equations for the calculation of conversion degree $X$ and the decomposition temperature $T_{\mathrm{f}}$ as followed:

$d \mathrm{X} / d \mathrm{t}=\mathrm{K}_{\mathrm{c}} \cdot \Delta \mathrm{h}_{\mathrm{R}} /\left(3 \cdot\left(\mathrm{T}_{\mathrm{g}}-\mathrm{T}_{\mathrm{F}}\right) \cdot\left(\mathrm{r}_{\mathrm{s}} / \alpha+\mathrm{r}_{\mathrm{s}}{ }^{2} / \lambda \cdot\left((1-\mathrm{X})^{-1 / 3}-1\right)\right)^{-1}\right)$

$d \mathrm{X} / d \mathrm{t}=\mathrm{K}_{\mathrm{c}} \cdot \mathrm{R}_{\mathrm{c}} \cdot \mathrm{T}_{\mathrm{F}} /\left(3\left(\mathrm{P}_{\mathrm{eq}}-\mathrm{P}_{\mathrm{g}}\right) \cdot\left(\mathrm{r}_{\mathrm{s}} / \beta+\mathrm{r}_{\mathrm{s}}^{2} / \mathrm{D}_{\mathrm{P}} \cdot\left((1-\mathrm{X})^{-1 / 3}\right)+\mathrm{r}_{\mathrm{s}} / k \cdot(1-\mathrm{X})^{-2 / 3}\right)^{-1}\right)$

where $t$ is time, $X$ is decomposition rate of limestone, $d_{\mathrm{s}}$ is the diameter of the particles, $\alpha, \lambda, \kappa, D s, \beta$ are performance parameters of limestone decomposition process.

With Eqs.(1)-(2), the conversion degree of limestone can be calculated as function of time, which provides foundation data for thermal decomposition reaction kinetics mechanism.

\section{Reaction kinetics mechanism model}

Kinetics research is to obtain the three factors of decomposition reaction kinetics: reaction mechanism model function and former factor and activation energy. At present, there are many kinds of limestone decomposition reaction kinetics model, which can be generally divided into three categories: random nucleation and subsequent growth, diffusion control, phase interface reaction mechanism model. Determining the limestone reaction mechanism model is the dominant part of decomposition reaction kinetics. Among the research of reaction mechanism, reaction mechanism model and the corresponding kinetic parameters are obtained by linear fitting method which combined with the conversion degree.

Reaction kinetics equations of solid particles are as follows ${ }^{[6]}$ :

$$
d \mathrm{X} / d \mathrm{t}=k(\mathrm{~T}) \cdot f(\mathrm{X})
$$

or

$$
g(\mathrm{X})=k(\mathrm{~T}) \cdot \mathrm{t}
$$

where $f(X)$ and $g(X)$ are reaction mechanism functions, $k(T)$ is reaction rate constant.

Different mechanism function $g(X)$ of decomposition reaction are summarized in Table 1.

\begin{tabular}{|c|c|c|}
\hline & reaction dynamics mechanism & mechanism function $g(X)$ \\
\hline 1 & one-dimensional diffusion & $\overline{X^{2}}$ \\
\hline 2 & two-dimensional diffusion, cylindrical symmetry & $X+(1-X) \ln (1-X)$ \\
\hline 3 & three dimensional diffusion, $\mathrm{n}=2$ & $\left(1-(1-X)^{1 / 3}\right)^{2}$ \\
\hline 4 & three dimensional diffusion cylindrical symmetry & $1-2 X / 3-(1-X)^{2 / 3}$ \\
\hline 5 & $\begin{array}{l}\text { Random nucleation and subsequent growth, } \\
\qquad \mathrm{n}=1 / 2, \mathrm{~m}=2\end{array}$ & $(-\ln (1-X))^{1 / 2}$ \\
\hline 6 & $\begin{array}{l}\text { Random nucleation and subsequent growth, } \\
\qquad \mathrm{n}=1 / 3, \mathrm{~m}=3\end{array}$ & $(-\ln (1-X))^{1 / 3}$ \\
\hline 7 & $\begin{array}{l}\text { phase interface reaction, cylindrical symmetry, } \\
\qquad \mathrm{n}=1 / 2\end{array}$ & $1-(1-X)^{1 / 2}$ \\
\hline 8 & $\begin{array}{l}\text { phase interface reaction, spherical symmetric, } \\
\qquad \mathrm{n}=1 / 3\end{array}$ & $1-(1-X)^{1 / 3}$ \\
\hline
\end{tabular}

Table 1 The mechanism function of the decomposition reaction

\section{Reaction kinetic parameters}

Reaction rate constant $k(T)$ in kinetic equation has a close relationship with temperature, these relation equation were proposed by Arrhenius and Vant't Hoff ${ }^{[7]}$. Among these equations, equilibrium constant and temperature equation is commonly used, which is put forward by 
Arrhenius $^{[8]}$ as followes:

$$
k(\mathrm{~T})=A \exp (-E / R T)
$$

where $A$ refers to the pre-exponential factor, $E$ refers to activation energy, $R$ refers to molar gas constant, $T$ refers to temperature.

Reaction rate constant $k(T)$ is obtained after the determination of decomposition reaction mechanism. Corresponding parameters (the activation energy $E$ and the pre-exponential factors $A$ ) can be obtained combining concentration profile of limestone.

\section{Results and discussion}

Based on the decomposition process, using MATLAB software, numerical analyses of limestone reaction kinetic can be investigated. Firstly, based on limestone decomposition five sub-processes, numerical equation of decomposition reaction is solved, and the concentration profile with three different particle sizes are obtained. And then, combined with reaction dynamics equation, reaction kinetics mechanism model of limestone particle are determined and corresponding kinetic parameters are calculated.

\section{Calculation of concentration profile}

In combination with numerical equation, the concentration profiles of three different particle size, at $900,950,1000^{\circ} \mathrm{C}$ are calculated, shown in Figure 1-3, respectively. Limestone properties are listed in Table 2.
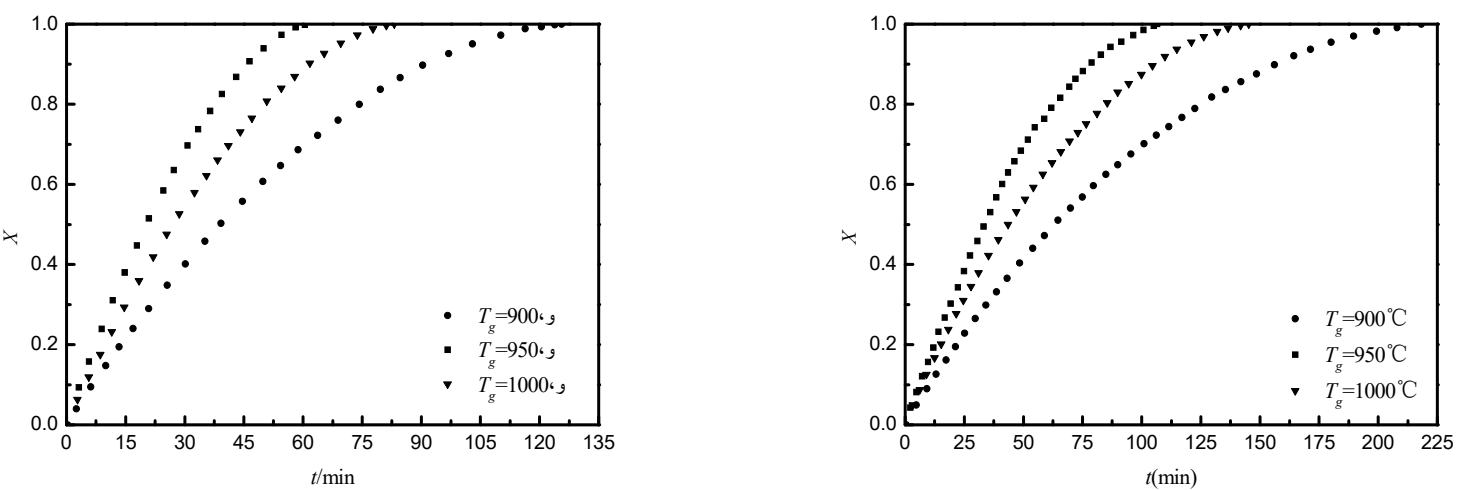

Fig. 1 concentration profile with $\mathrm{d}=20 \mathrm{~mm} \quad$ Fig. 2 concentration profile with $\mathrm{d}=30 \mathrm{~mm}$

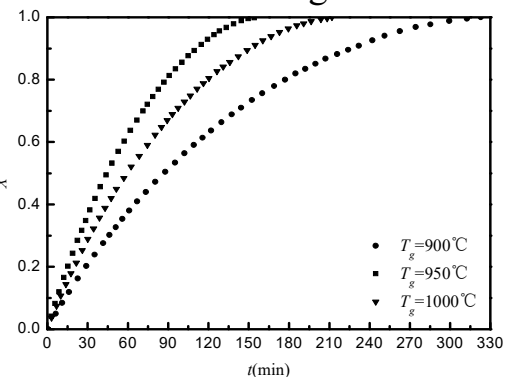

Fig. 3 concentration profile with $\mathrm{d}=40 \mathrm{~mm}$

Table 2 Decomposition performance parameters of limestone particles ${ }^{[9]}$

\begin{tabular}{cccccc}
\hline parameter & $\alpha$ & $\lambda$ & $\kappa$ & $D_{\mathrm{p}}$ & $\beta$ \\
\hline & $45 \mathrm{~W} \cdot\left(\mathrm{m}^{2} \mathrm{~K}\right)^{-1}$ & $0.7 \mathrm{~W} \cdot(\mathrm{mK})^{-1}$ & $0.006 \mathrm{~m} \cdot \mathrm{s}^{-1}$ & $0.2 \mathrm{~m}^{2} \cdot \mathrm{s}^{-1}$ & $0.5 \mathrm{~m} \cdot \mathrm{s}^{-1}$ \\
\hline
\end{tabular}

The concentration profiles match well with the profile of thermos-gravimetric experiment. In the initial stage, decomposition reaction rate raises rapidly. The longer the decomposition time is, the lower the reaction coefficient is. This is due to activity of limestone. The quantity of calcium oxide increases, which will block the pores of limestone. Calcium oxide layer makes gas diffusion resistance increases with the decrease of reaction rate. 
In Figure 3, it can be concluded that temperature is the main factor on limestone decomposition rate, the higher the temperature is, the faster the decomposition rate of limestone is. Taking the diameter $\mathrm{d}=20 \mathrm{~mm}$ limestone as example, at $45 \mathrm{~min}$, limestone decomposition rate reaches $51 \%$ and $82 \%$, when temperature is $900^{\circ} \mathrm{C}$ and $1000^{\circ} \mathrm{C}$, respectively. This is because that the heat transfer rate is growing with the temperature. It is illustrated that the decomposition time increases with the rising of particle size. The increasing of particle size leads to the decrease of heat transfer rate.

\section{Determination of decomposition reaction mechanism model}

Based on the concentration profile above, the mechanism model of decomposition reaction are determined by solid particle dynamics equation. The decomposition rates of three different particle sizes are taken into dynamic equation. The linear regression is conducted between mechanism function $g(X)$ and time $t$, where imports correlation coefficient $R$ to check the linear fitting between mechanisms function $g(X)$ and time $t$. It shows that the greater the correlation coefficient $R$ is, the more obvious is the linearity between mechanism function $g(X)$ and time $t$. Thus, the suitable reaction mechanism is determined by correlation coefficient $R$. The linear regression results of three different particle size are shown in Table 3, 4, 5.

Table 3 Linear regression results with a diameter $d=20 \mathrm{~mm}$

\begin{tabular}{ccccccc}
\hline \multirow{2}{*}{ Reaction dynamics mechanism } & \multicolumn{3}{c}{ Correlation coefficient $\mathrm{R}$} & \multicolumn{3}{c}{$\mathrm{k}(\mathrm{T}) \cdot 10^{-3}$} \\
\cline { 2 - 7 } & $900^{\circ} \mathrm{C}$ & $950{ }^{\circ} \mathrm{C}$ & $1000^{\circ} \mathrm{C}$ & $900^{\circ} \mathrm{C}$ & $950^{\circ} \mathrm{C}$ & $1000^{\circ} \mathrm{C}$ \\
\hline one-dimensional diffusion & 0.994 & 0.995 & 0.994 & 4.95 & 9.13 & 13.93 \\
two-dimensional diffusion, cylindrical symmetry & 0.991 & 0.986 & 0.983 & 4.78 & 8.58 & 12.87 \\
three dimensional diffusion, $\mathrm{n}=2$ & 0.987 & 0.988 & 0.988 & 3.40 & 2.63 & 3.92 \\
three dimensional diffusion cylindrical symmetry & 0.979 & 0.972 & 0.966 & 1.48 & 6.28 & 9.46 \\
Random nucleation and subsequent growth, $\mathrm{n}=1 / 2$ & 0.989 & 0.987 & 0.988 & 8.80 & 15.77 & 23.06 \\
Random nucleation and subsequent growth, $\mathrm{n}=1 / 3$ & 0.982 & 0.981 & 0.980 & 5.81 & 10.55 & 15.62 \\
phase interface reaction, cylindrical symmetry, $\mathrm{n}=1 / 2$ & 0.999 & 0.999 & 0.998 & 4.18 & 7.23 & 11.48 \\
phase interface reaction, spherical symmetric, $\mathrm{n}=1 / 3$ & 0.988 & 0.983 & 0.977 & 3.35 & 6.24 & 9.14 \\
\hline
\end{tabular}

Table 4 Linear regression results with a diameter $d=30 \mathrm{~mm}$

\begin{tabular}{ccccccc}
\hline \multirow{2}{*}{ Reaction dynamics mechanism } & \multicolumn{3}{c}{ Correlation coefficient $\mathrm{R}$} & \multicolumn{3}{c}{$\mathrm{k}(\mathrm{T}) \cdot 10^{-3}$} \\
\cline { 2 - 7 } & $900^{\circ} \mathrm{C}$ & $950^{\circ} \mathrm{C}$ & $1000^{\circ} \mathrm{C}$ & $900^{\circ} \mathrm{C}$ & $950^{\circ} \mathrm{C}$ & $1000^{\circ} \mathrm{C}$ \\
\hline one-dimensional diffusion & 0.993 & 0.994 & 0.995 & 2.84 & 5.29 & 7.94 \\
two-dimensional diffusion, cylindrical symmetry & 0.993 & 0.989 & 0.988 & 2.73 & 4.89 & 7.38 \\
three dimensional diffusion, $\mathrm{n}=2$ & 0.984 & 0.985 & 0.986 & 1.92 & 1.49 & 2.26 \\
three dimensional diffusion cylindrical symmetry & 0.983 & 0.976 & 0.973 & 0.84 & 3.54 & 5.34 \\
Random nucleation and subsequent growth, $\mathrm{n}=1 / 2$ & 0.990 & 0.991 & 0.990 & 4.87 & 8.54 & 13.05 \\
Random nucleation and subsequent growth, $\mathrm{n}=1 / 3$ & 0.979 & 0.978 & 0.980 & 3.22 & 5.77 & 8.74 \\
phase interface reaction, cylindrical symmetry, $\mathrm{n}=1 / 2$ & 0.998 & 0.999 & 0.999 & 2.38 & 4.34 & 6.44 \\
phase interface reaction, spherical symmetric, $\mathrm{n}=1 / 3$ & 0.988 & 0.984 & 0.982 & 2.14 & 3.23 & 5.39 \\
\hline
\end{tabular}

Table 5 Linear regression results with a diameter $d=40 \mathrm{~mm}$

\begin{tabular}{|c|c|c|c|c|c|c|}
\hline \multirow{2}{*}{ Reaction dynamics mechanism } & \multicolumn{3}{|c|}{$\begin{array}{c}\text { Correlation coefficient } \\
\text { R }\end{array}$} & \multicolumn{3}{|c|}{$\begin{array}{l}\text { Reaction rate constant } \\
\qquad\left(10^{-3}\right)\end{array}$} \\
\hline & $900^{\circ} \mathrm{C}$ & $950^{\circ} \mathrm{C}$ & $1000^{\circ} \mathrm{C}$ & $900^{\circ} \mathrm{C}$ & $950^{\circ} \mathrm{C}$ & $1000^{\circ} \mathrm{C}$ \\
\hline one-dim & 0.991 & 0.993 & 0.994 & 1.92 & 3.58 & 5.36 \\
\hline two-dimensional diffusion, cylindrical symmetry & 0.959 & 0.993 & 0.992 & 1.84 & 3.36 & 5.09 \\
\hline three dimensional diffusion, $n=2$ & 0.979 & 0.983 & 0.984 & 1.29 & 1.02 & 1.56 \\
\hline three dimensional diffusion cylindrical symmetry & 0.986 & 0.982 & 0.980 & 0.57 & 2.36 & 3.59 \\
\hline Random nucleation and subsequent growth, $n=1 / 2$ & 0.989 & 0.989 & 0.989 & 3.24 & 5.85 & 9.08 \\
\hline Random nucleation and subsequent growth, $n=1 / 3$ & 0.975 & 0.977 & 0.980 & 2.15 & 3.89 & 5.99 \\
\hline phase interface reaction, cylindrical symmetry, $n=1 / 2$ & 0.995 & 0.997 & 0.998 & 1.59 & 2.93 & 4.54 \\
\hline phase interface reaction, spherical symmetric, $n=1 / 3$ & 0.991 & 0.988 & 0.987 & 1.43 & 2.43 & 3.76 \\
\hline
\end{tabular}

The correlation coefficient $R$ of phase interface reaction mechanism (cylindrical symmetry) with 
a diameter $\mathrm{d}=20 \mathrm{~mm}$ is most close to 1 , mechanism function $g(X)$ has the most significant linear relationship with time $t$. It is illustrated that the limestone with a diameter $d=20 \mathrm{~mm}$ conforms to phase interface reaction mechanism (cylindrical symmetry). In a similar way, the limestone with a diameter $d=30 \mathrm{~mm}$ and $40 \mathrm{~mm}$ also conform to phase interface reaction mechanism (cylindrical symmetry).It is considered that phase interface reaction mechanism occurs in a geometric interface without thickness, unreacted nuclear grows across the surface, the reaction interface gradually advance to the inside nuclear with the decomposition reaction.

Overall, it can be seen that particle size and the environment temperature had no significant effect on mechanism model. Limestones with three different particle size, at $900,950,1000^{\circ} \mathrm{Care}$ accord with phase interface reaction mechanism (cylindrical symmetry), and the corresponding reaction mechanism function is $g(X)=1-(1-X)^{1 / 2}$.

\section{Calculation of limestone decomposition reaction kinetics parameter}

The corresponding reaction rate constant is obtained from phase interface reaction mechanism (cylindrical symmetry). Combining with Arrhenius equation, activation energy $\mathrm{E}$ and the pre-exponential factor are solved by the slope and intercept of the fitted curve. Reaction kinetic parameters of three different particle size are listed in Table 6.

Table 6 Kinetic parameters with three different particle sizes

\begin{tabular}{ccc}
\hline diameter $\mathrm{mm}$ & activation energy $\mathrm{E}(\mathrm{kcal} / \mathrm{mol})$ & pre-exponential factor $\ln \mathrm{A}(/ \mathrm{s})$ \\
\hline 20 & 32.219 & 8.736 \\
30 & 32.015 & 8.376 \\
40 & 33.638 & 7.982 \\
\hline
\end{tabular}

Table 6 illustrates that activation energy with three different diameter are $30-34.9 \mathrm{kcal} / \mathrm{mol}$, and pre-exponential factor are $7.5-9 \mathrm{~s}^{-1}$. Activation energy increases with the rising of limestone particle size. With the increasing of particle diameter, specific surface area of limestone reduces, response speed becomes slower, heat and mass transfer is hampered. Due to the compensation effect, activation energy increases and the former factor decreases. The tendency of activation energy and pre-exponential factor are accord with reported studies, which declares the accuracy of dynamics mechanism model and parameters using numerical method in this study.

\section{Summary}

Reaction mechanism of limestones with diameter of $20,30,40 \mathrm{~mm}$, at $900,950,1000^{\circ} \mathrm{C}$ are accord with phase interface reaction mechanism (cylindrical symmetry), the corresponding reaction mechanism function is $g(X)=1-(1-X)^{1 / 2}$. Corresponding reaction activation energy is ranging from 30 to $34 \mathrm{kcal} / \mathrm{mol}$ and the pre-exponential factor is ranging from 7.5 to $9 \mathrm{~s}^{-1}$, which conform to reported studies. These results provide practical significance on establishment the thermal simulation equation in lime kilns and decomposition reaction conditions.

\section{References}

[1] S.J.Wang and J.D.Lu: J Chem Ceram Soc, Vol.31(2003), No.8, pp 11-14

[2] H. Chen, S.H. Zhang: Inorganic Chemicals Industry, Vol.45(2013), No.9,pp 11-14

[3] C.Cheng, E. Specht, G. Kehse: ZKG international, Vol.60(2007), No.1, pp 51-61

[4] H. Kainer, E. Specht: ZKG, Zement-Kalk-Gips, Edition A, Vol.39(1986), No.5, pp259-268

[5] E. Specht, G. Warnecke, D.H. Do, et al:OS Schmidt - fg-kalk-moertel, Vol.40(1987), No.2, pp126-131

[6] R.Z. Hu, S.L. Gao, F.Q. Zhao, et al. Beijing: Science press, 5-15. (2008)

[7] J.H. Chen, C.R. Li, Beijing: Science press, 96-118. (1985)

[8] M. Samtani, D. Dollimore, K. Alexander: Thermochim Acta, Vol.392(2002), pp 135-145 
[9] H.D. Duc, E. Specht: Numerical Simulation of Heat and Mass Transfer of Limestone Decomposition in Normal Shaft Kiln in the ASME/JSME 2011 8th Thermal Engineering Joint Conference. USA: ASME (2011) 